\title{
Article \\ Effect of Physiotherapy Treatment in the Autonomic Activation and Pain Perception in Male Patients with Non-Specific Subacute Low Back Pain
}

\author{
Vanesa Abuín-Porras ${ }^{1}$ D, Vicente Javier Clemente-Suárez ${ }^{1,2, * \mathbb{D}}$, Gonzalo Jaén-Crespo ${ }^{1}$, \\ Emmanuel Navarro-Flores ${ }^{3}\left(\mathbb{D}\right.$, Helios Pareja-Galeano ${ }^{1}$ (D) and Carlos Romero-Morales ${ }^{1}$ (D) \\ 1 Faculty of Sport Sciences, Universidad Europea de Madrid, Villaviciosa de Odón, 28670 Madrid, Spain; \\ vanesa.abuin@universidadeuropea.es (V.A.-P.); gjaencrespo@gmail.com (G.J.-C.); \\ helios.pareja@universidadeuropea.es (H.P.-G.); carlos.romero@universidadeuropea.es (C.R.-M.) \\ 2 Grupo de Investigación en Cultura, Educación y Sociedad, Universidad de la Costa, \\ 080002 Barranquilla, Colombia \\ 3 Frailty Research Organized Group (FROG), Department of Nursing, Faculty of Nursing and Podiatry, \\ University of Valencia, 46001 Valencia, Spain; emmanuel.navarro@uv.es \\ * Correspondence: vctxente@yahoo.es
}

Citation: Abuín-Porras, V.; Clemente-Suárez, V.J.; Jaén-Crespo, G.; Navarro-Flores, E.;

Pareja-Galeano, H.; Romero-Morales, C. Effect of Physiotherapy Treatment in the Autonomic Activation and Pain Perception in Male Patients with Non-Specific Subacute Low Back Pain. J. Clin. Med. 2021, 10, 1793. https://doi.org/10.3390/ jcm10081793

Academic Editor: Tomoyuki Takura

Received: 17 February 2021

Accepted: 18 April 2021

Published: 20 April 2021

Publisher's Note: MDPI stays neutral with regard to jurisdictional claims in published maps and institutional affiliations.

Copyright: (c) 2021 by the authors. Licensee MDPI, Basel, Switzerland. This article is an open access article distributed under the terms and conditions of the Creative Commons Attribution (CC BY) license (https:// creativecommons.org/licenses/by/ $4.0 /)$.
Abstract: Introduction: Physiotherapy treatment is a common intervention for low back pain (LBP) patients. These interventions have been related to physiological effects in the central nervous system. Thus, the aim of this study was to analyze the effect of physiotherapy treatment in patients with LBP in the autonomic nervous system activation and subjective pain perception of patients. Methods: A total of 30 male subjects diagnosed with non-specific subacute LBP received a 50 min session consisting of (a) a manual therapy based on joint mobilization and soft tissues techniques in the lumbo-pelvic area, (b) a stretching program, and (c) motor control exercises of the core muscles. The autonomic modification of participants was assessed prior to and after the physiotherapy treatment. Results: Heart rate variability (HRV) analysis reported a significant increase in average RR $(p=0.001)$, $\operatorname{RMSSD}(p=0.008), \operatorname{LRMSSD}(p=0.001), \operatorname{SDNN}(p=0.005)$, and PNN50 $(p=0.024)$ after the session. Frequency-domain measures showed a significant increase in LF $(p=0.030)$ and HF $(p=0.014)$, and a decrease in LF/HF ratio $(p=0.046)$. A significant decrease was found in minimum HR values $(p=0.001)$ and average HR $(p=0.001)$. Moreover, maximal HR decreased its value from $116.7 \pm 26.1$ to $113.7 \pm 40.8$ after intervention. In addition, subjective pain perception (VAS scores) was significantly lower $(p=0.001)$ in the post-session assessment. Conclusions: Physiotherapy treatment produced an increase in parasympathetic nervous system activation and a decrease in subjective pain perception in non-specific subacute LBP patients.

Keywords: nervous system; low back pain; physical therapy

\section{Introduction}

Through the past decades, noninvasive treatments in the management of chronic low back pain has been a topic of research [1,2]. Amongst the most studied noninvasive methods, physiotherapy has been commonly included in LBP management protocols [3]. Physiotherapy treatment for LBP generally includes a combination of mobilization, massage, and different manual therapy techniques [4,5], combined with active therapies such as motor control exercise [6-8], Pilates exercise [9], and others [10]. Some authors, analyzed different approaches offered for the treatment of back pain, suggesting the use of massage as a complement to other therapies such as mobilization or exercise [11]. Several studies reported the effectiveness of this techniques to certain degree, especially in the short term $[3,5,12,13]$. Despite the high prevalence of back pain, few treatment methods have a critical evidence [14]. 
Changes in the activity of the autonomic nervous system after the application of certain physiotherapy techniques have been reported by some authors, especially invasive techniques such as percutaneous needle electrolysis and acupuncture [15-19], but also electrotherapy techniques such as interferential currents [20]. Mild vagal reactions have also been observed during the application of noninvasive physiotherapy techniques, such as craniosacral therapy [21] and massage [22-24].

The clinical interest of sympathetic (SNS) and parasympathetic nervous system (PNS) activity in this context relies on the role they play in the regulation of pain states, especially chronic pain. Tracy et al. performed a metanalysis in this topic, concluding that a decrease in parasympathetic activation is commonly found in chronic pain patients [25]. A common method for evaluation of autonomous system activity is the assessment of heart rate variability (HRV) [26]. In fact, in chronic pain patients, a decreased $\mathrm{HRV}$ is a common finding, probably influenced by a constant activation of the stress response and persistent SNS activation caused by pain mechanisms [27]. HRV has also been studied in several clinical conditions [28-30] and sport performance [31]. Thus, the interest on the assessment of HRV as a sign of autonomic nervous system disfunction has led to including this evaluation during the application of various physiotherapeutic techniques, such as massage [24], craniosacral therapy [21], acupuncture [15,27], spinal manipulative therapy [32], and percutaneous nerve stimulation [17-19]. These techniques, although very common in physiotherapy practice, are rarely used in low back pain treatment in an isolated way. To the authors' knowledge, this study is the first to explore autonomic activation after a common combination of physiotherapy techniques usually applied in daily clinical practice for patients with low back pain.

The aim of this study was to analyze the effect of a physiotherapy treatment in patients with LBP in the autonomous nervous system activation and subjective pain perception of patients. The initial hypothesis was that the physiotherapy treatment would decrease the sympathetic autonomous activation and pain perception of patients.

\section{Methods}

\subsection{Design}

The present study was a prospective clinical trial developed from September to December 2020, following the Template for Intervention Description and Replication (TIDieR) guidelines [33].

\subsection{Participants}

In this study, 30 volunteer male patients ( $35.1 \pm 9.2$ years; $1.71 \pm 0.1 \mathrm{~m} ; 64.2 \pm 11.1 \mathrm{~kg}$; $21.9 \pm 0.9 \mathrm{BMI})$ diagnosed with non-specific subacute LBP by a medical doctor were included. The recruitment was carried out by a medical doctor with more than 25 years of experience. The inclusion criteria were as follows: $\geq 18$ years old, LBP (severity $\geq 3 / 10$ in visual analogue scale), and a current episode of 2-12 weeks with the presence of back pain symptoms. Exclusion criteria were: fractures, inflammatory arthropathies, spine disturbances, metabolic diseases, any disc condition, other LBP interventions or treatments, and other physical or mental disturbances reported in the clinical exam [34].

The sample size for the present study was calculated by employing a one-sample $t$-test with Jpower tool (Jamovi software), with a power of $0.80, \alpha$ error of 0.05 , and an effect size of 0.5 , resulting in a total sample of 30 subjects.

\subsection{Ethics}

The whole procedure was performed following the Declaration of Helsinki (revised in Brazil, 2013) and approved by the Ethics Committee of the European University of Madrid (Spain) (CIPI/18/074). Before starting the study, all participants were informed about the process to be carried out and gave their voluntary written informed consent. 


\subsection{Physiotherapy Intervention}

All the patients went through 1 physiotherapy session consisting in a manual therapy intervention based on joint mobilization and soft tissues techniques in the lumbo-pelvic area [35]; stretching program; and motor control exercises of the core muscles-transversus abdominis, internal oblique, external oblique, and multifidus-following Ford et al.'s guidelines. All the individuals started the motor control exercises in unloaded positions, and the progression depended on good control and endurance with no pain during exercises [36]. The length of the sessions were $50 \mathrm{~min}$.

\subsection{Procedure}

The autonomic modification of participants was assessed prior to and after the physiotherapy treatment. For this aim, participants were laying in a supine position for $5 \mathrm{~min}$ for HRV measurement in a stretcher placed in a room with controlled temperature, following previous research protocols [37].

The autonomic activation of the participants was analyzed by HRV measure using Polar V800 equipment (Polar, Kempele, Finland), following previously reported research protocols [38]. This evaluation allowed us to objectively determine the participants' autonomic activation in a non-invasive, easily accessible, and affordable way. The intervals between successive heartbeats (RR intervals) were analyzed by the Kubios HRV software (version 2.2, Biosignal Analysis and Medical Imaging Group, University of Kuopio, Finland). Since previous research found different sensitivity depending on the HRV domain analysis and the characteristic of the context [39-42], we analyzed 2 HRV domains to detect modification in HRV in this context:

Time-domain (nonspectral): Based on the assessment of the intervals between normal heartbeats. During the statistical analysis, generally all the QRS (graphical combination of $\mathrm{Q}, \mathrm{R}$, and $\mathrm{S}$ waves) complexes, the duration between consecutive QRS complexes (NN interval), or the instantaneous heart rates during continuous electrocardiogram (ECG) recordings are determined [43]. We recorded the following time-domain indices: average RR intervals (ms); RMSSD (ms): the square root of the mean value of the sum of squared differences of all successive R-R intervals; LRMSSD (ms): logarithm of the square root of the mean value of the sum of squared differences of all successive R-R intervals: SDNN (ms): the standard deviation of the interbeat interval from which artifacts were removed (NN); and PNN50: the percentage of differences between adjacent normal R-R intervals more than $50 \mathrm{~ms}$.

Frequency-domain/spectral measures (spectral): This analysis provides information on how the power is distributed as a function of frequency. This provides us with smoother spectral components that can be distinguished as independent from preselected frequency bands and easy postprocessing of the spectrum with an automatic calculation of low- and high-frequency power components and an easy identification of the central frequency of each component, as well as accurate estimation even on a small number of samples [44]. HF and LF (ms) were measured in order to analyze the peaks of parasympathetic, highfrequency component, frequency range: $0.15-0.40 \mathrm{~Hz}(\mathrm{HF})$, and sympathetic low-frequency component frequency range: $0.04-0.15 \mathrm{~Hz}(\mathrm{LF})$ values. The total power (ms) and LF/HF ratio was also measured.

Finally, the minimum, maximal, and average heart rate were also measured.

To assess the subjective pain perception, we employed a visual analogue scale (VAS) of $10 \mathrm{~mm}$ (from 0 no pain to 10 maximum pain) at baseline and immediately after the session [45].

\subsection{Statistical Analyses}

Data were analyzed using the Statistical Package for the Social Sciences (SPSS) version 21.0 (SPSS Inc., Chicago, IL, USA). The Kolmogorov-Smirnov test was used to test the normality and homogeneity of the sample in each variable. To analyze the modification of studied variables after the physiotherapy treatment, we conducted an independent $t$-test for related 
samples. The level of significance for all the comparisons was set at $p \leq 0.05$, and the effect size of results was calculated with the Cohen's D. In addition, Pearson correlation analysis was employed to test the relation between VAS and HRV variables.

\section{Results}

Data are presented as mean $\pm \mathrm{SD}$. RR abbreviation corresponds to the interval between successive " $R$ " points (peaks), root mean square of successive differences (RMSSD) corresponds to the square root of the mean of the squares of the successive differences between adjacent beat to beat intervals, LRMSSD stands for the logarithm of the square root of the mean value of the sum of squared differences of all successive R-R intervals, SDNN stands for the standard deviation of all normal RR intervals, RMSSD corresponds to the square root of the mean of the sum of the squared differences between adjacent normal R-R intervals, PNN50 stands for the percentage of differences between adjacent normal R-R intervals more than $50 \mathrm{~ms}$, LF stands for low frequency, and HF stands for high frequency.

The HRV analysis showed a significant increase in average RR $(p=0.001)$, RMSSD $(p=0.008)$, LRMSSD $(p=0.001)$, SDNN $(p=0.005)$, and PNN50 $(p=0.024)$ after the treatment. These data from time-domain parameters indicated a higher post-session parasympathetic activation. Concerning frequency-domain measures, the data showed a significant increase in LF $(p=0.030)$ and HF $(p=0.014)$, and a decrease in LF/HF ratio $(p=0.046)$ (Table 1).

Table 1. Modification of heart rate variability and visual analogue scale variables after the physiotherapy treatment.

\begin{tabular}{|c|c|c|c|c|c|c|}
\hline & Pre & Post & $\%$ Change & $\mathbf{T}$ & $p$ & Cohen's D \\
\hline Average RR (ms) & $738.2 \pm 99.1$ & $817.9 \pm 108.3$ & 10.8 & -7.123 & 0.001 & 0.81 \\
\hline RMSSD (ms) & $38.6 \pm 14.4$ & $52.5 \pm 24.0$ & 36.0 & -2.837 & 0.008 & 0.97 \\
\hline LRMSSD (ms) & $3.59 \pm 0.31$ & $3.89 \pm 0.41$ & 8.4 & -3.654 & 0.001 & 0.97 \\
\hline SDNN (ms) & $69.3 \pm 16.8$ & $80.1 \pm 18.7$ & 15.6 & -3.069 & 0.005 & 0.64 \\
\hline PNN50 (\%) & $14.4 \pm 15.8$ & $22.0 \pm 12.3$ & 52.8 & -2.377 & 0.024 & 0.48 \\
\hline Total power (ms) & $2542.7 \pm 1191.9$ & $4325.7 \pm 3354.1$ & 70.1 & -3.045 & 0.005 & 1.50 \\
\hline $\mathrm{LF}(\mathrm{ms})$ & $2065.4 \pm 1028.5$ & $2916.2 \pm 1899.1$ & 41.2 & -2.284 & 0.030 & 0.83 \\
\hline $\mathrm{HF}(\mathrm{ms})$ & $473.5 \pm 310.4$ & $1217.2 \pm 1687.5$ & 157.1 & -2.628 & 0.014 & 2.40 \\
\hline LF/HF ratio & $5.54 \pm 3.40$ & $4.54 \pm 3.10$ & -18.1 & 2.087 & 0.046 & 0.29 \\
\hline $\begin{array}{l}\text { Minimum HR } \\
(\mathrm{bpm})\end{array}$ & $64.1 \pm 5.8$ & $58.2 \pm 6.8$ & -4.7 & 5.769 & 0.001 & 0.50 \\
\hline Maximal HR (bpm) & $116.7 \pm 26.1$ & $113.7 \pm 40.8$ & -2.6 & .256 & 0.725 & 0.11 \\
\hline Average HR (bpm) & $82.3 \pm 10.8$ & $74.6 \pm 9.4$ & -9.4 & 7.532 & 0.001 & 0.71 \\
\hline VAS & $7.3 \pm 0.8$ & $5.5 \pm 1.2$ & -24.7 & 8.537 & 0.001 & 2.25 \\
\hline
\end{tabular}

RMSSD— the square root of the mean value of the sum of squared differences of all successive R-R intervals; LRMSSD—logarithm of the square root of the mean value of the sum of squared differences of all successive R-R intervals; SDNN—standard deviation of all normal RR intervals; PNN50 - percentage of differences between adjacent normal R-R intervals more than $50 \mathrm{~ms}$; LF-low frequency; HF—high frequency; ms—-milliseconds; bpm—beat per minute; HR—heart rate; VAS—visual analogue scale.

On the contrary, a significant decrease in minimum HR values $(p=0.001)$ and average HR $(p=0.001)$ was observed, which indicated a preponderancy of PNS activation. Moreover, maximal HR decreased its value from $116.7 \pm 26.1$ to $113.7 \pm 40.8$ after intervention (Table 1). In addition, subjective pain perception (VAS scores) was significantly lower $(p=0.001)$ in the post-session assessment.

A negative, significant correlation was found between RMSSD, LRMSSD, SDNN, PNN50, total power, LF and HF, and VAS scores (Table 2), indicating a decrease of subjective pain perception related to an increase of parasympathetic activation. Moreover, a positive significant correlation was found between minimum HR and VAS scores. 
Table 2. Correlation analysis between visual analogue scale and heart rate variability variables.

\begin{tabular}{ccc}
\hline Variable & $\mathbf{r}$ & $\boldsymbol{p}$ \\
\hline RR interval & -0.092 & 0.486 \\
\hline RMS SD & -0.447 & 0.000 \\
\hline LRMS SD & -0.451 & 0.000 \\
\hline SDN N & -0.256 & 0.048 \\
\hline PNN 50 & -0.245 & 0.059 \\
\hline Total power & -0.402 & 0.001 \\
\hline LF & -0.232 & 0.012 \\
\hline HF & -0.378 & 0.003 \\
\hline LF/HF ratio & 0.161 & 0.220 \\
\hline Minimum HR & 0.262 & 0.043 \\
\hline Maximal HR & -0.165 & 0.207 \\
\hline Average HR & 0.150 & 0.252 \\
\hline
\end{tabular}

RMSSD-the square root of the mean value of the sum of squared differences of all successive R-R intervals, LRMSSD-logarithm of the square root of the mean value of the sum of squared differences of all successive R-R intervals; SDNN—standard deviation of all normal RR intervals; RMSSD—square root of the mean of the sum of the squared differences between adjacent normal R-R intervals; PNN50-percentage of differences between adjacent normal R-R intervals more than $50 \mathrm{~ms}$; LF-low frequency; HF-high frequency; ms—milliseconds; bpm—beat per minute; HR—heart rate; VAS—visual analogue scale.

\section{Discussion}

The aim of this study was to analyze the effect of a physiotherapy session in patients with non-specific subacute low back pain in terms of autonomous nervous system activation and subjective pain perception. The initial hypothesis was confirmed since after the physiotherapy session, the parameters of sympathetic autonomous activation and pain perception of the subjects decreased.

Analyzing the autonomic activation modifications after the intervention, we found how there was a direct impact on sympathetic-vagal balance. The increase in the timedomain parameters highlighted the increase in parasympathetic activation. Regarding the frequency domain, we found a general increase in autonomic activation with a significant higher total power, which was reflected in a significant increase of HF and LF variables [37]. Specifically, the sympathetic-vagal balance represented in the LF/HF ratio decreased significantly, highlighting the increased parasympathetic activation of participants, a fact also corroborated with the lower numbers in minimum and average HR parameters.

Concerning the sensibility of the measures, all the HRV parameters evaluated in this study showed a high sensibility to monitor autonomic modifications. This results differed partially with another previous studies, since depending on the context and population evaluated, different sensibility of HRV variables were found [38,42,46-48].

In this study, a statistically significant inverse correlation was found between RMSSD, LRMSSD, SDNN, PNN50, total power, LF and HF, and subjective pain perception. According to these results, parasympathetic activation seems to have an impact in decreasing pain perception mechanisms. Previous research highlighted that patients with chronic pain reported disturbances in sympathetic-parasympathetic balance, showing a decreased high frequency HRV, probably due to excessive SNS activation [25]. In particular, central sensitization phenomena had been studied in chronic low back pain patients [49-52]. There is still further research to be conducted to understand the complexity of chronic pain in this specific subgroup of population, but autonomic imbalance seems to play a determinant role in the perpetuation of symptoms in chronic pain [53]. The intervention conducted in the present research is a potentially useful tool to use in these patients. 
Previous studies found how physiotherapy soft tissues techniques produce an increase in the parasympathetic activation [20-22]. Guan et al. [22] focused on the benefits on HF of massage applied to children in a pediatric intensive care unit. Their results are consistent with our study, showing a significant increase of HF (75\%) and LF (56\%) post-session. In this study, HF increased by $157 \%$ and LF by $41 \%$. It has to be noted that Guan et al.'s study was conducted in critically ill children, and thus the effects they found may differ with ours due to their particular health status. Wälchli et al. [27], in their study on the effects of rhythmical massage, reported an increase of HRV, which is in line with the results of the present study. Buttagat et al. [24] explored the effects of a massage technique in HRV and pressure pain threshold in a sample of patients with back pain. Their results were concurrent with ours in terms of increased HRV parameters (total power and HF), indicating post-treatment increases in parasympathetic activation.

PNS activation produced by physiotherapy treatment could be clinically relevant in certain populations with high levels of SNS activation. The effects of stress through autonomic system analysis have been studied in several groups of subjects. A recent systematic review from Bustamante et al. [54] focused on the effects of stress in the military population and the consequences for their autonomic balance, enhancing the necessity for finding coping strategies [55-57]. Other authors have also explored autonomic balance in several sports [47,58-64], enhancing the importance of PNS activation in performance. These populations could potentially benefit from physiotherapy interventions according with our results.

Future research lines could explore the combination of physiotherapy treatment with other interventions that have been proved as useful for increasing PNS activation, such as physical activity programs [65], psychological approaches for stress control, or mindfulness [66].

Several limitations can be reported for the present study. For example, the sample was composed entirely by men. This should be taken into account in order to not extrapolate the results to the entire population. In this line, future research is needed that includes both genders. In addition, the evaluation of the HRV only in the short term must also be taken into consideration. Future research is needed with a mid- and long-time follow-up. Finally, another study limitation for the present work was that only one HRV measure was recorded.

\section{Practical Applications}

The results of the present research highlighted the validity of HRV portable system to monitor modifications in the autonomic nervous system of patients. This system could be easily implemented in clinics as a method to control the evolution and efficiency of treatment in this populations.

\section{Conclusions}

A physiotherapy session including joint mobilization, soft tissue techniques, a stretching program, and motor control exercises of the core muscles produces an increase in parasympathetic nervous system activation and a decrease in subjective pain perception in non-specific subacute LBP patients.

Author Contributions: Conceptualization, V.A.-P., E.N.-F. and C.R.-M.; data curation, V.J.C.-S. Clemente; formal analysis, V.J.C.-S.; investigation, V.A.-P., G.J.-C. and C.R.-M.; methodology, G.J.C. and E.N.-F.; project administration, V.J.C.-S.; resources, G.J.-C.; supervision, C.R.-M.; validation, H.P.-G.; writing-original draft, V.A.-P., V.J.C.-S. and H.P.-G.; writing-review and editing, V.J.C.-S., E.N.-F., H.P.-G. and C.R.-M. All authors have read and agreed to the published version of the manuscript.

Funding: This research received no external funding.

Institutional Review Board Statement: The study was approved by the Ethics Committee of the European University of Madrid (Spain) (CIPI/18/074). 
Informed Consent Statement: Informed consent was obtained from all subjects involved in the study.

Data Availability Statement: Data available from the authors under request.

Conflicts of Interest: The authors declare no conflict of interest.

\section{References}

1. Will, J.S.; Bury, D.C.; Miller, J.A. Mechanical Low Back Pain. Am. Fam. Phys. 2018, 98, 421-428.

2. Oliveira, C.B.; Maher, C.G.; Pinto, R.Z.; Traeger, A.C.; Lin, C.-W.C.; Chenot, J.-F.; van Tulde, M.; Koes, B.W. Clinical practice guidelines for the management of non-specific low back pain in primary care: An updated overview. Eur. Spine J. 2018, 27, 2791-2803. [CrossRef]

3. Cuenca-Martínez, F.; Cortés-Amador, S.; Espí-López, G.V. Effectiveness of classic physical therapy proposals for chronic nonspecific low back pain: A literature review. Phys. Ther. Res. 2018, 21, 16-22. [CrossRef] [PubMed]

4. Poquet, N.; Lin, C.-W.C.; Heymans, M.W.; van Tulder, M.W.; Esmail, R.; Koes, B.W.; Maher, C.G. Back schools for acute and subacute non-specific low-back pain. Cochrane Database Syst. Rev. 2016, 4, CD008325. [CrossRef] [PubMed]

5. Bervoets, D.C.; Luijsterburg, P.A.J.; Alessie, J.J.N.; Buijs, M.J.; Verhagen, A.P. Massage therapy has short-term benefits for people with common musculoskeletal disorders compared to no treatment: A systematic review. J. Physiother. 2015, 61, 106-116. [CrossRef]

6. Saragiotto, B.T.; Maher, C.G.; Yamato, T.P.; Costa, L.O.P.; Menezes Costa, L.C.; Ostelo, R.W.J.G.; Macedo, L.G. Motor control exercise for chronic non-specific low-back pain. Cochrane Database Syst. Rev. 2016. [CrossRef]

7. Michaelson, P.; Holmberg, D.; Aasa, B.; Aasa, U. High load lifting exercise and low load motor control exercises as interventions for patients with mechanical low back pain: A randomized controlled trial with 24-month follow-up. J. Rehabil. Med. 2016, 48, 456-463. [CrossRef] [PubMed]

8. Macedo, L.G.; Saragiotto, B.T.; Yamato, T.P.; Costa, L.O.P.; Menezes Costa, L.C.; Ostelo, R.W.J.G.; Maher, C.G. Motor control exercise for acute non-specific low back pain. Cochrane Database Syst. Rev. 2016, 2, CD012085. [CrossRef]

9. Eliks, M.; Zgorzalewicz-Stachowiak, M.; Zeńczak-Praga, K. Application of Pilates-based exercises in the treatment of chronic non-specific low back pain: State of the art. Postgrad. Med. J. 2019, 95, 41-45. [CrossRef]

10. Owen, P.J.; Miller, C.T.; Mundell, N.L.; Verswijveren, S.J.J.M.; Tagliaferri, S.D.; Brisby, H.; Bowe, S.J.; Belavy, D.L. Which specific modes of exercise training are most effective for treating low back pain? Network meta-analysis. Br. J. Sports Med. 2020, 54, 1279-1287. [CrossRef]

11. Blanco-Morales, M.; Abuín-Porras, V.; Romero-Morales, C.; De La Cueva-Reguera, M.; De-La-Cruz-Torres, B.; Rodríguez-Costa, I. Implementation of a Classroom Program of Physiotherapy among Spanish Adolescents with Back Pain: A Collaborative Study. Int. J. Environ. Res. Public Health 2020, 17, 4806. [CrossRef] [PubMed]

12. Ulger, O.; Demirel, A.; Oz, M.; Tamer, S. The effect of manual therapy and exercise in patients with chronic low back pain: Double blind randomized controlled trial. J. Back Musculoskelet. Rehabil. 2017, 30, 1303-1309. [CrossRef]

13. Furlan, A.D.; Giraldo, M.; Baskwill, A.; Irvin, E.; Imamura, M. Massage for low-back pain. Cochrane Database Syst. Rev. 2015. [CrossRef]

14. Van Tulder, M.W.; Assendelft, W.J.J.; Koes, B.W.; Bouter, L.M. Method guidelines for systematic reviews in the Cochrane Collaboration Back Review Group for spinal disorders. Spine 1997, 22, 2323-2330. [CrossRef]

15. Anderson, B.; Nielsen, A.; McKee, D.; Jeffres, A.; Kliger, B. Acupuncture and Heart Rate Variability: A Systems Level Approach to Understanding Mechanism. Explore 2012, 8, 99-106. [CrossRef]

16. Huang, H.; Zhong, Z.; Chen, J.; Huang, Y.; Luo, J.; Wu, J.; Liao, H.; Zhen, E.; Lin, R.; Fasmer, O.B.; et al. Effect of Acupuncture at Ht7 on Heart Rate Variability: An Exploratory Study. Acupunct. Med. 2015, 33, 30-35. [CrossRef]

17. García Bermejo, P.; De La Cruz Torres, B.; Naranjo Orellana, J.; Albornoz Cabello, M. Autonomic Responses to Ultrasound-Guided Percutaneous Needle Electrolysis: Effect of Needle Puncture or Electrical Current? J. Altern. Complement. Med. 2018, 24, 69-75. [CrossRef]

18. Torres, B.D.L.C.; Cabello, M.A.; Bermejo, P.G.; Orellana, J.N. Autonomic Responses to Ultrasound-Guided Percutaneous Needle Electrolysis of the Patellar Tendon in Healthy Male Footballers. Acupunct. Med. 2016, 34, 275-279. [CrossRef] [PubMed]

19. García Bermejo, P.; de la Cruz Torres, B.; Naranjo Orellana, J.; Albornoz Cabello, M. Autonomic activity in women during percutaneous needle electrolysis. Eur. J. Integr Med. 2017, 11, 53-58. [CrossRef]

20. Jin, H.-K.; Hwang, T.-Y.; Cho, S.-H. Effect of Electrical Stimulation on Blood Flow Velocity and Vessel Size. Open Med. 2017, 12, 5-11. [CrossRef] [PubMed]

21. Girsberger, W.; Bänziger, U.; Lingg, G.; Lothaller, H.; Endler, P.-C. Heart rate variability and the influence of craniosacral therapy on autonomous nervous system regulation in persons with subjective discomforts: A pilot study. J. Integr. Med. 2014, 12, 156-161. [CrossRef]

22. Guan, L.; Collet, J.-P.; Yuskiv, N.; Skippen, P.; Brant, R.; Kissoon, N. The effect of massage therapy on autonomic activity in critically ill children. Evid. Based Complement. Alternat Med. 2014, 2014, 656750. [CrossRef] [PubMed]

23. Seifert, G.; Kanitz, J.-L.; Rihs, C.; Krause, G.; Witt, K.; Voss, A. Rhythmical massage improves autonomic nervous system function: A single-blind randomised controlled trial. J. Integr. Med. 2018, 16, 172-177. [CrossRef] [PubMed] 
24. Buttagat, V.; Eungpinichpong, W.; Chatchawan, U.; Kharmwan, S. The immediate effects of traditional Thai massage on heart rate variability and stress-related parameters in patients with back pain associated with myofascial trigger points. J. Bodyw. Mov. Ther. 2011, 15, 15-23. [CrossRef] [PubMed]

25. Tracy, L.M.; Ioannou, L.; Baker, K.S.; Gibson, S.J.; Georgiou-Karistianis, N.; Giummarra, M.J. Meta-analytic evidence for decreased heart rate variability in chronic pain implicating parasympathetic nervous system dysregulation. Pain 2016, 157, 7-29. [CrossRef] [PubMed]

26. Navarro-Lomas, G.; De-la-O, A.; Jurado-Fasoli, L.; Castillo, M.J.; Femia, P.; Amaro-Gahete, F.J. Assessment of autonomous nerve system through non-linear heart rate variability outcomes in sedentary healthy adults. PeerJ 2020, 8, e10178. [CrossRef]

27. Wälchli, C.; Saltzwedel, G.; Krüerke, D.; Kaufmann, C.; Schnorr, B.; Rist, L.; Eberhard, J.; Decker, M.; Simões-Wüst, A.P. Physiologic Effects of Rhythmical Massage: A Prospective Exploratory Cohort Study. J. Altern. Complement. Med. 2014, 20, 507-515. [CrossRef]

28. de la Cruz Torres, B.; López López, C.; Naranjo Orellana, J. Analysis of heart rate variability at rest and during aerobic exercise: A study in healthy people and cardiac patients. Br. J. Sports Med. 2008, 42, 715-720. [CrossRef]

29. Telles, S.; Sharma, S.K.; Gupta, R.K.; Bhardwaj, A.K.; Balkrishna, A. Heart rate variability in chronic low back pain patients randomized to yoga or standard care. BMC Complement. Altern. Med. 2016, 16, 279. [CrossRef]

30. Naumann, J.; Grebe, J.; Kaifel, S.; Weinert, T.; Sadaghiani, C.D.; Huber, R. Effects of hyperthermic baths on depression, sleep and heart rate variability in patients with depressive disorder: A randomized clinical pilot trial. BMC Complement. Altern. Med. 2017, 17, 172. [CrossRef] [PubMed]

31. Naranjo, J.; De La Cruz, B.; Sarabia, E.; De Hoyo, M.; Domínguez-Cobo, S. Heart Rate Variability: A Follow-up in Elite Soccer Players Throughout the Season. Endoscopy 2015, 36, 881-886. [CrossRef]

32. Bakken, A.G.; Axén, I.; Eklund, A.; O’Neill, S. The effect of spinal manipulative therapy on heart rate variability and pain in patients with chronic neck pain: A randomized controlled trial. Trials 2019, 20, 590. [CrossRef] [PubMed]

33. Hoffmann, T.C.; Glasziou, P.P.; Boutron, I.; Milne, R.; Perera, R.; Moher, D.; Altman, D.G.; Barbour, V.; Macdonald, H.; Johnston, M.; et al. Better reporting of interventions: Template for intervention description and replication (TIDieR) checklist and guide. BMJ 2014, 348, g1687. [CrossRef] [PubMed]

34. Evans, R.; Haas, M.; Schulz, C.; Leininger, B.; Hanson, L.; Bronfort, G. Spinal manipulation and exercise for low back pain in adolescents: A randomized trial. Pain 2018, 159, 1297-1307. [CrossRef] [PubMed]

35. Teychenne, M.; Lamb, K.E.; Main, L.; Miller, C.; Hahne, A.; Ford, J.; Rosenbaum, S.; Belavy, D. General strength and conditioning versus motor control with manual therapy for improving depressive symptoms in chronic low back pain: A randomised feasibility trial. PLoS ONE 2019, 14, e0220442. [CrossRef]

36. Ford, J.; Hahne, A.; Pui Chan, A.Y.; Surkitt, L.D. A classification and treatment protocol for low back disorders Part 3-Functional restoration for intervertebral disc related disorders. Phys. Ther. Rev. 2012, 17, 55-75. [CrossRef]

37. Clemente-Suárez, V.J.; Fernandes, R.J.; Arroyo-Toledo, J.J.; Figueiredo, P.; Gonzalez Vera, J.M.; Vilas-Boas, J.P. Autonomic adaptation after traditional and reverse swimming training periodizations. Acta Physiol. Hung. 2015, 102, 105-113. [CrossRef] [PubMed]

38. Ramírez-Adrados, A.; Fernández-Martínez, S.; Martínez-Pascual, B.; Gonzalez-de-Ramos, C.; Fernández-Elías, V.E.; ClementeSuárez, V.J. Psychophysiological stress response of physio-therapy last year students in his final degree dissertation. Physiol. Behav. 2020, 222, 112928. [CrossRef]

39. Delgado-Moreno, R.; Robles-Pérez, J.J.; Aznar-Laín, S.; Clemente-Suárez, V.J. Effect of Experience and Psychophysiological Modification by Combat Stress in Soldier's Memory. J. Med. Syst. 2019, 43, 150. [CrossRef]

40. Belinchon-deMiguel, P.; Clemente-Suárez, V.J. Psychophysiological, Body Composition, Biomechanical and Autonomic Modulation Analysis Procedures in an Ultraendurance Mountain Race. J. Med. Syst. 2018, 42, 32. [CrossRef]

41. Clemente-Suárez, V.J.; Beltrán-Velasco, A.I.; Bellido-Esteban, A.; Ruisoto-Palomera, P. Autonomic Adaption to Clinical Simulation in Psychology Students: Teaching Applications. Appl. Psychophysiol. Biofeedback 2018, 43, 239-245. [CrossRef] [PubMed]

42. Beltrán-Velasco, A.I.; Bellido-Esteban, A.; Ruisoto-Palomera, P.; Clemente-Suárez, V.J. Use of Portable Digital Devices to Analyze Autonomic Stress Response in Psychology Objective Structured Clinical Examination. J. Med. Syst. 2018, 42, 35. [CrossRef]

43. Tornero-Aguilera, J.F.; Sanchez-Molina, J.; Fernández-Elías, V.E.; Clemente-Suárez, V.J. Psychophysiological Stress Response of Novice Cavers in a Speleology Route. Wilderness Environ. Med. 2020, 31, 259-265. [CrossRef] [PubMed]

44. Sánchez-Conde, P.; Beltrán-Velasco, A.I.; Clemente-Suárez, V.J. Influence of psychological profile in autonomic response of nursing students in their first hospital clinical stays. Physiol. Behav. 2019, 207, 99-103. [CrossRef] [PubMed]

45. Williamson, A.; Hoggart, B. Pain: A review of three commonly used pain rating scales. J. Clin. Nurs. 2005, 14, 798-804. [CrossRef] [PubMed]

46. Sánchez-Molina, J.; Robles-Pérez, J.J.; Clemente-Suárez, V.J. Effect of Parachute Jump in the Psychophysiological Response of Soldiers in Urban Combat. J. Med. Syst. 2017, 41, 99. [CrossRef]

47. Figueiredo, D.H.; Figueiredo, D.H.; Moreira, A.; Gonçalves, H.R.; Stanganelli, L.C.R. Effect of Overload and Tapering on Individual Heart Rate Variability, Stress Tolerance, and Intermittent Running Performance in Soccer Players During a Preseason. J. Strength Cond. Res. 2019, 33, 1222-1231. [CrossRef] [PubMed]

48. Fuentes, J.P.; Villafaina, S.; Collado-Mateo, D.; de la Vega, R.; Gusi, N.; Clemente-Suárez, V.J. Use of Biotechnological Devices in the Quantification of Psychophysiological Workload of Professional Chess Players. J. Med. Syst. 2018, 42, 40. [CrossRef] 
49. Sanzarello, I.; Merlini, L.; Rosa, M.A.; Perrone, M.; Frugiuele, J.; Borghi, R.; Faldini, C. Central sensitization in chronic low back pain: A narrative review. J. Back Musculoskelet. Rehabil. 2016, 29, 625-633. [CrossRef]

50. Huysmans, E.; Ickmans, K.; Van Dyck, D.; Nijs, J.; Gidron, Y.; Roussel, N.; Polli, A.; Moens, M.; Goudman, L.; De Kooning, M. Association Between Symptoms of Central Sensitization and Cognitive Behavioral Factors in People with Chronic Nonspecific Low Back Pain: A Cross-sectional Study. J. Manip. Physiol. Ther. 2018, 41, 92-101. [CrossRef]

51. Clark, J.R.; Nijs, J.; Smart, K.; Holmes, P.; Yeowell, G.; Goodwin, P.C. Prevalence of Extreme Trait Sensory Profiles and Personality Types in Nonspecific Chronic Low Back Pain with Predominant Central Sensitization: Secondary Analysis of an International Observational Study. Pain Phys. 2019, 22, E181-E190. [CrossRef]

52. Clark, J.R.; Nijs, J.; Yeowell, G.; Holmes, P.; Goodwin, P.C. Trait Sensitivity, Anxiety, and Personality Are Predictive of Central Sensitization Symptoms in Patients with Chronic Low Back Pain. Pain Pract. 2019, 19, 800-810. [CrossRef]

53. Benarroch, E.E. Pain-autonomic interactions. Neurol. Sci. Off. J. Ital. Neurol Soc. Ital. Soc. Clin. Neurophysiol. 2006, 27 (Suppl. S2), S130-S133. [CrossRef] [PubMed]

54. Bustamante-Sánchez, Á.; Tornero-Aguilera, J.F.; Fernández-Elías, V.E.; Hormeño-Holgado, A.J.; Dalamitros, A.A.; ClementeSuárez, V.J. Effect of Stress on Autonomic and Cardiovascular Systems in Military Population: A Systematic Review. Cardiol. Res. Pract. 2020, 2020, 7986249. [CrossRef] [PubMed]

55. Clemente-Suárez, V.J.; de la Vega, R.; Robles-Pérez, J.J.; Lautenschlaeger, M.; Fernández-Lucas, J. Experience modulates the psychophysiological response of airborne warfighters during a tactical combat parachute jump. Int. J. Psychophysiol. Off. J. Int Organ. Psychophysiol. 2016, 110, 212-216. [CrossRef] [PubMed]

56. Clemente-Suárez, V.J.; Robles-Pérez, J.J.; Fernández-Lucas, J. Psychophysiological response in parachute jumps, the effect of experience and type of jump. Physiol. Behav. 2017, 179, 178-183. [CrossRef]

57. Clemente-Suárez, V.J.; Robles-Pérez, J.J. Mechanical, Physical, and Physiological Analysis of Symmetrical and Asymmetrical Combat. J. Strength Cond. Res. 2013, 27, 2420-2426. [CrossRef]

58. Campos, B.T.; Penna, E.M.; Rodrigues, J.G.S.; Diniz, M.; Mendes, T.T.; Filho, A.F.C.; Franchini, E.; Nakamura, F.Y.; Prado, L.S. Influence of Autonomic Control on the Specific Intermittent Performance of Judo Athletes. J. Hum. Kinet. 2018, 64, 99-109. [CrossRef]

59. Cataldo, A.; Zangla, D.; Cerasola, D.; Vallone, V.; Grusso, G.; Presti, R.L.; Traina, M. Influence of baseline heart rate variability on repeated sprint performance in young soccer players. J. Sports Med. Phys. Fit. 2015, 56, 491-496.

60. Soares-Caldeira, L.F.; de Souza, E.A.; de Freitas, V.H.; Franzói de Moraes, S.M.; Leicht, A.; Nakamura, F.Y. Effects of additional repeated sprint training during preseason on performance, heart rate variability, and stress symptoms in futsal players: A randomized controlled trial. J. Strength Cond. Res. 2014, 28, 2815-2826. [CrossRef]

61. Flatt, A.A.; Hornikel, B.; Esco, M.R. Heart rate variability and psychometric responses to overload and tapering in collegiate sprint-swimmers. J. Sci. Med. Sport 2017, 20, 606-610. [CrossRef] [PubMed]

62. Plews, D.J.; Laursen, P.B.; Stanley, J.; Kilding, A.; Buchheit, M. Training adaptation and heart rate variability in elite endurance athletes: Opening the door to effective monitoring. Sports Med. 2013, 43, 773-781. [CrossRef] [PubMed]

63. Flatt, A.A.; Howells, D. Effects of varying training load on heart rate variability and running performance among an Olympic rugby sevens team. J. Sci. Med. Sport 2019, 22, 222-226. [CrossRef] [PubMed]

64. Williams, S.; West, S.; Howells, D.; Kemp, S.P.; Flatt, A.A.; Stokes, K. Modelling the HRV Response to Training Loads in Elite Rugby Sevens Players. J. Sports Sci. Med. 2018, 17, 402-408. [PubMed]

65. Ambrose, K.R.; Golightly, Y.M. Physical exercise as non-pharmacological treatment of chronic pain: Why and when. Best Pract. Res. Clin. Rheumatol. 2015, 29, 120-130. [CrossRef] [PubMed]

66. Hilton, L.; Hempel, S.; Ewing, B.A.; Apaydin, E.; Xenakis, L.; Newberry, S.; Colaiaco, B.; Maher, A.R.; Shanman, R.M.; Sorbero, M.E.; et al. Mindfulness Meditation for Chronic Pain: Systematic Review and Meta-analysis. Ann. Behav. Med. 2017, 51, 199-213. [CrossRef] 